\section{CANCER AND ITS TREATMENT.}

(1) The Conquest of Cancer: a Plan of Campaign. By C. W. Saleeby. Pp. xxiv +397 . (London: Chapman and Hall, Ltd., 1907.) Price 7s. 6d. net. (2) Cancer: Relief of Pain and Possible Cure. By Skene Keith and George E. Keith. Pp. ix $+1_{55}$. (London: Adam and Charles Black, I908.) Price 2s. $6 d$. net.

(I) I $\mathrm{N}$ the "Conquest of Cancer" Dr. Saleeby gives a full account of the trophoblastic theory of cancer, and of the evidence which led Dr. Beard to suggest the pancreatic enzymes as a rational treatment for the disease.

Briefly stated, Dr. Beard believes that as in the development of lower animals there is an alternation of an asexual and of a sexual generation, so in the higher animals there is an asexual larval stage upon which the embryo proper develops. The larval tissue or trophoblast is transitory, and its germ cells should entirely disappear; but the germ cells may wander widely, and the natural degeneration they should undergo may not ensue. If the latter event happen, the ultimate fate of the aberrant germ cells varies; they may lie quiescent throughout life, or for some reason they may start into active proliferation. Should the latter event occur a cancerous growth is the result.

Now the normal degeneration and disappearance of the trophoblastic tissue coincide, according to Dr. Beard, with the development of the activity of the pancreas, and are due, according to him, to the digestive action of the pancreatic enzymes. If the pancreatic enzymes thus cause the disappearance of the trophoblastic tissue of the embryo, it may be expected that the same injected into a person suffering from a cancerous growth will similarly cause the growth to degenerate. The pancreatic enzymes attack and digest trophoblastic tissue, whether of the embryo or of the cancer, but have no effect on the normal tissues. This in brief is the theory on which the pancreatic enzyme treatment is based.

In the second half of the volume practical details are considered-cancer and surgery, preparation of ferments and details of treatment, claims of the treatment, and results obtained. Dr. Saleeby, of course, is enthusiastic; other accounts by no means support his enthusiasm. Nevertheless, it is to be hoped that the method will have a thorough trial with approved preparations of the ferments.

In the final portion of the book the medical journals which have criticised the enzyme treatment come in for some hard sayings on the part of Dr. Saleeby. Nature, too, does not escape. Dr. Saleeby says :-

" NATURE is not a medical journal, but the leading scientific journal in this country. It published (December 20, 1906) an adverse comment on my Pall Mall Gazette articles, and in its reply to the letter which its remarks drew from Dr. Beard stated that 'the pancreatic enzymes must be injected into the neighbourhood of the growth or used locally; how then could the secondary growths in internal organs be attacked! Until this can be done, no cure for cancer will have been obtained.' Dr. Beard's second letter, correcting this most important and inexcusable error, was not inserted, and the statement was allowed to stand."

The qualifying words "we believe" (which appear before "the pancreatic enzymes," \&c., in the original) are omitted from this quotation, and "this inexcusable error" was not allowed to stand, but was corrected in Nature of February 28,1907, p. 424 . If this be a sample of Dr. Saleeby's accuracy, a doubt must arise as to the exactness of some of his other quotations.

(2) In the introduction to the second book, "Cancer," the authors remark, "We gave trypsin $x$ very extensive trial, but were completely disappointed in its use." The treatment advocated is the injection of a mixture of iodipin (an organic iodine combination), cacodylate of iron (an arsenic preparation), and cinnimate of sodium. The authors claim that this treatment markedly relieves the pain and other symptoms of cancer, and occasionally seems to cure.

R. T. H.

\section{OUR BOOK SHELF. \\ Mosses and Liverworts: an Introduction to their Study, with Hints as to their Collection and Preservation. By H. T. Russell. Pp. xiii+200. (London: Sampson Low, Marston and Co., Ltd., I908.) Price $4 s .6 d$. net.}

Notwithstanding the frequent use of the term "lifehistory," the book under consideration only deals with the morphological side of the subject, and will be of greater service to systematists than to biologists. In the majority of systematic works, only just those structural features are countenanced that enable a student to determine the name of a given plant, the result being that a person may become fairly safe on the matter of names, whilst remaining quite innocent as to the general morphological and physiologicaI features of the group he is studying. The second type of book, dealing with morphology proper, cytology, physiology, \&c.; that is, the biological aspect of the plant, is usually carefully avoided by the systematist. The present book follows a mean of the two extremes, and contains much useful information that would enable the systematist better to appreciate the part played by mosses and liverworts in the scheme of nature, and the ways and means by which such part is played.

Commencing with habitats, a very interesting account is given of the broad effects produced in nature by these minute plants, and also of their likes and dislikes in connection with climate, geological formations, and the surrounding vegetation. Commencing with the germination of the spore, the general morphological features of the succeeding structures of the asexual and sexual stages of a moss are treated somewhat in detail. The various vegetative modes of reproduction are also explained with accuracy. Im dealing with the biological aspect of the subject, the author is not so much at home. Touching on the subject of fertilisation, it is stated:- "As a matter of fact we know no more of this process of fertilisation, what it is and how it is effected, than we know what life itself is and how it originated." Notwithstanding the occurrence of a few such blemishes, the book, as already stated, should prove of value to those students of mosses and liverworts whose sole knowledge of the structure of, these plants is obtained from systematic works.

Eleven plates of very good figures illustrate the majority of the structural features dealt with in the text. 